\title{
Value of transesophageal echocardiography in device closure of perimembranous ventricular septal defects in children via an ultraminimal intercostal incision
}

\author{
Jin $\mathrm{Yu}^{1}$, Jing $\mathrm{Ye}^{1}$, Zewei Zhang ${ }^{1}$, Xiuzhen Yang${ }^{1}$, Lianglong Ma ${ }^{1}$, Jingjing Qian ${ }^{1}$, Lei \\ Zhao $^{1}$, and Qiang Shu ${ }^{1}$ \\ ${ }^{1}$ Zhejiang University School of Medicine Children's Hospital
}

September 27, 2021

\begin{abstract}
Object: Investigate the value of transesophageal echocardiography (TEE) in perimembranous ventricular septal defect (PmVSD) closure via a left parasternal ultra-minimal trans intercostal incision in children. Methods: From January 2015 and December 2020, 212 children with PmVSD were performed device occlusion via an ultraminimal intercostal incision. TEE is used throughout the perioperative period, including TEE assessment, TEE-guided localization of the puncture site, TEE guidance. All patients were followed up using transthoracic echocardiography for over 6 months. Results: A total of 207 cases successfully occluded, the successful rate was 97 . 64\%. one hundred and forty-five patients had single orifice, and 62 patients had multiple orifices in the AMS. During the operation, the surgeon readjusted the device or replaced the larger device in 17 cases. After operation, there were 19 cases of slight residual shunts, 13 cases of pericardial effusion and 4 cases of pleural effusion. And all were back to normal during the 4- month follow-up period. Mild mitral regurgitation was presented in 1 patient and remained the same during the follow-up period. No other complications were found. Conclusions: TEE was used to evaluate and determine the defect in PmVSDs with an concentric occluder via a left parasternal ultra-minimal trans intercostal incision. TEE guidance and immediate postoperative efficacy evaluation are of great value, which can effectively guide the treatment of PmVSD occlusion.
\end{abstract}

\section{Hosted file}

Journal of Cardiac Surgery ; Value of transesophageal echocardiography in device closure of perimembran available at https://authorea.com/users/438118/articles/539384-value-of-transesophagealechocardiography-in-device-closure-of-perimembranous-ventricular-septal-defects-inchildren-via-an-ultraminimal-intercostal-incision 

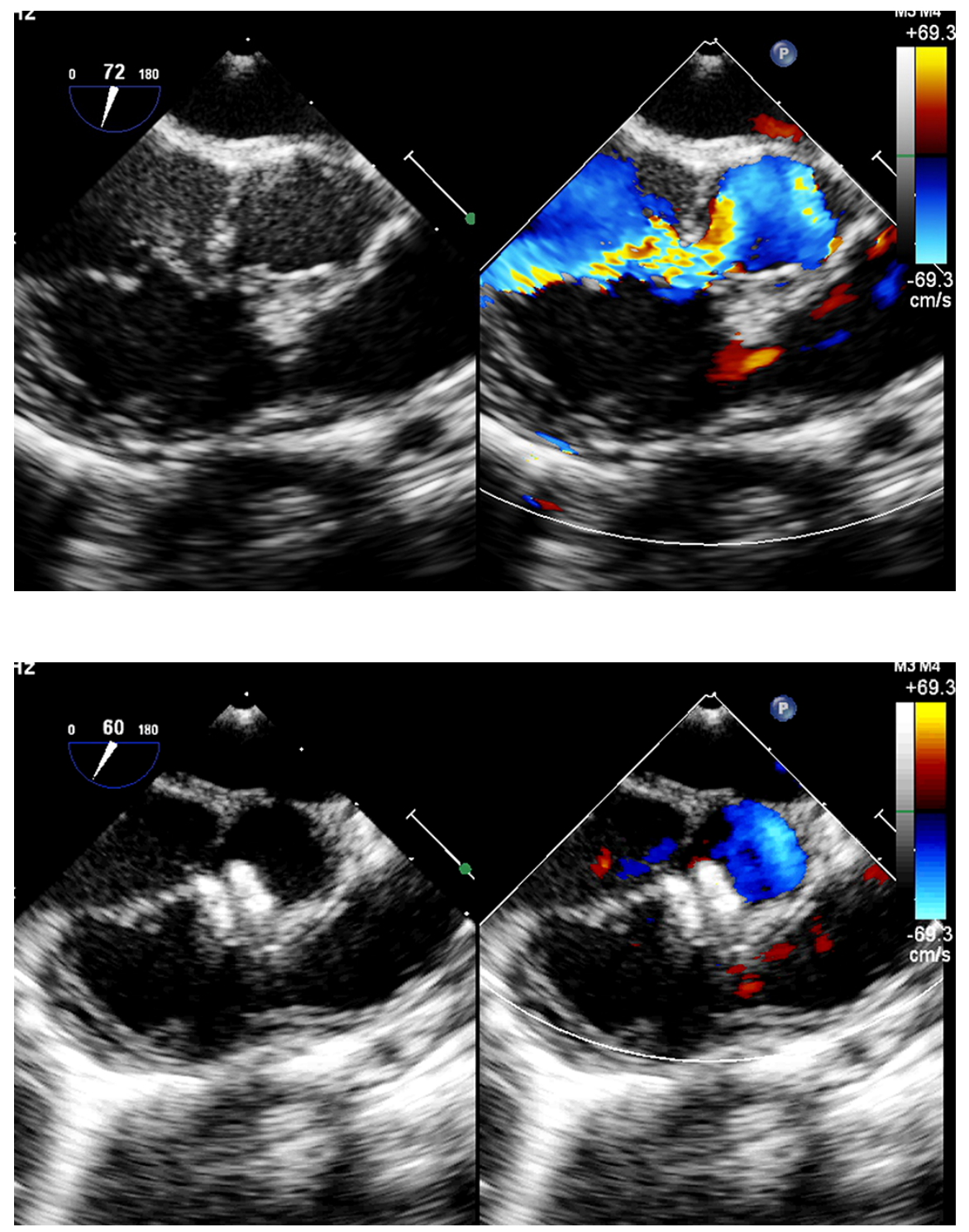

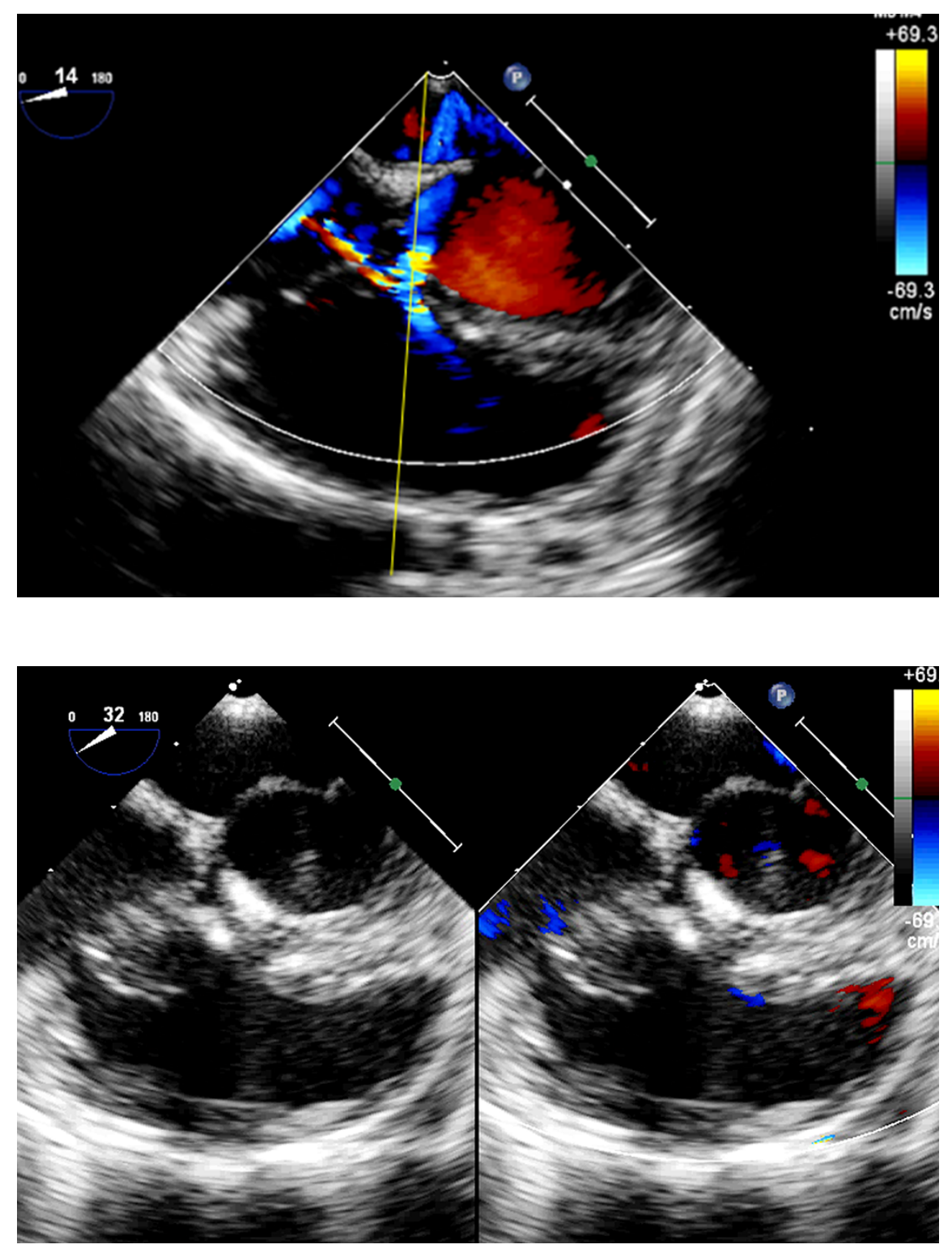

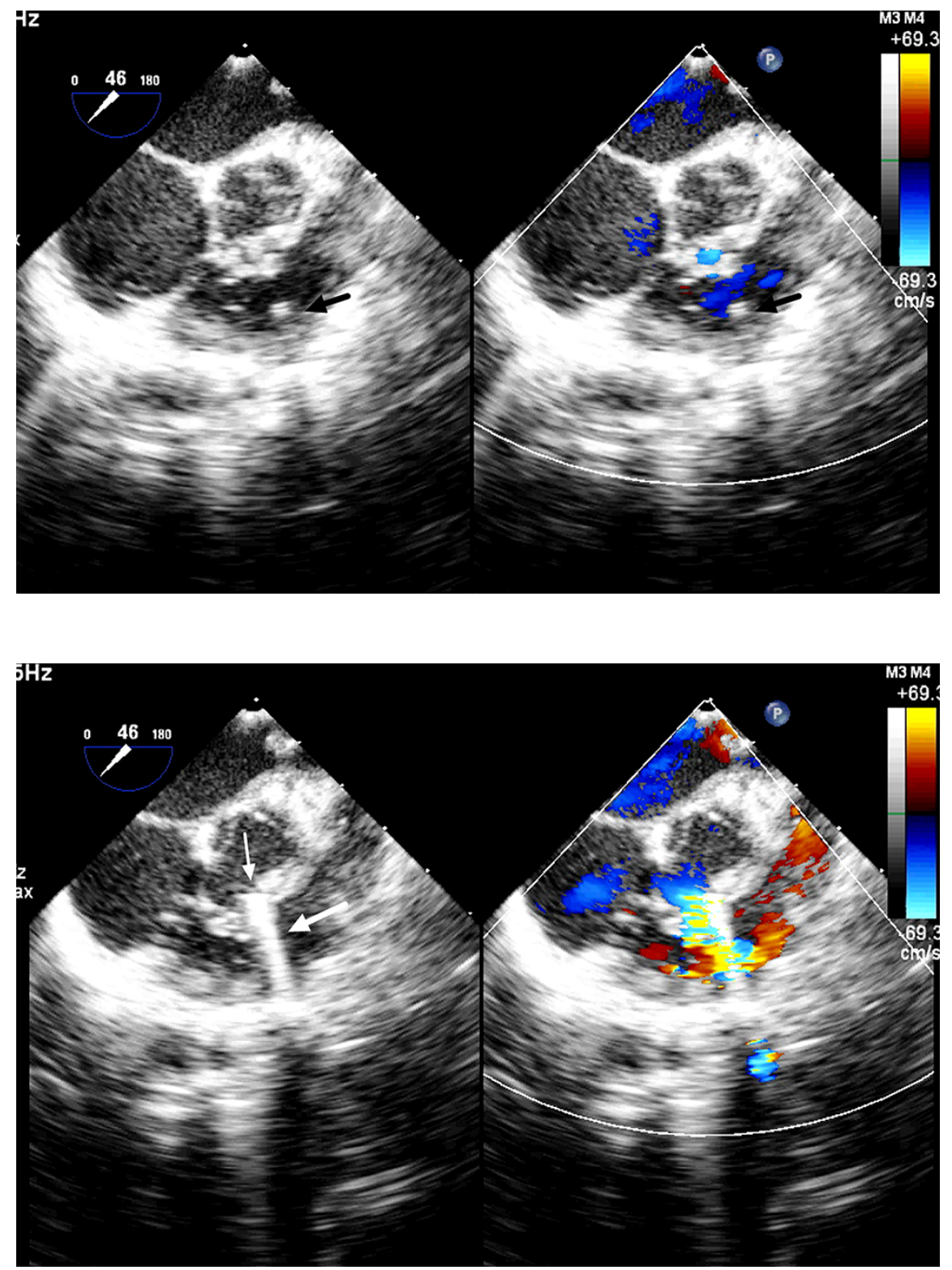

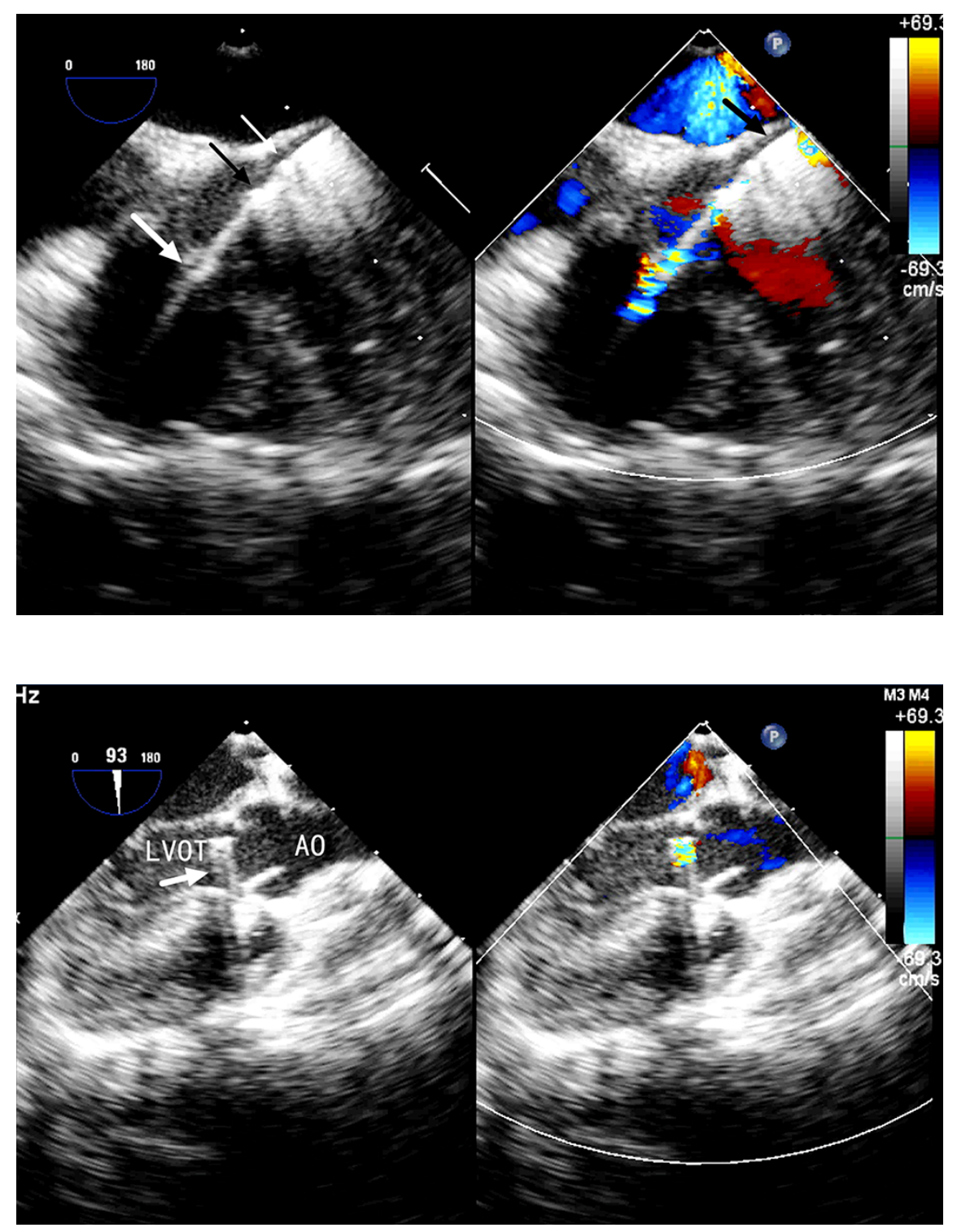


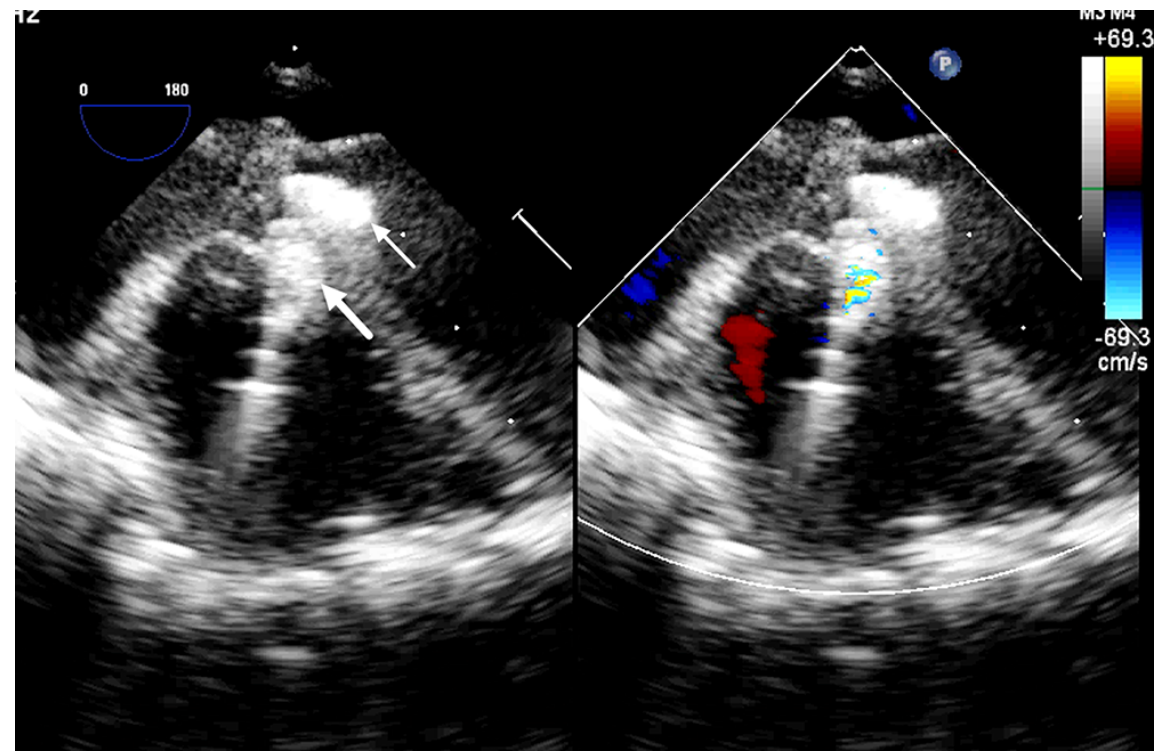

\section{Hosted file}

Table1.docx available at https://authorea.com/users/438118/articles/539384-value-oftransesophageal-echocardiography-in-device-closure-of-perimembranous-ventricular-septaldefects-in-children-via-an-ultraminimal-intercostal-incision

\section{Hosted file}

Table 2.docx available at https://authorea.com/users/438118/articles/539384-value-oftransesophageal-echocardiography-in-device-closure-of-perimembranous-ventricular-septaldefects-in-children-via-an-ultraminimal-intercostal-incision

\section{Hosted file}

Table 3.docx available at https://authorea.com/users/438118/articles/539384-value-oftransesophageal-echocardiography-in-device-closure-of-perimembranous-ventricular-septaldefects-in-children-via-an-ultraminimal-intercostal-incision

\section{Hosted file}

Table4.docx available at https://authorea.com/users/438118/articles/539384-value-oftransesophageal-echocardiography-in-device-closure-of-perimembranous-ventricular-septaldefects-in-children-via-an-ultraminimal-intercostal-incision 